www.jmscr.igmpublication.org

Impact Factor (SJIF): 6.379

Index Copernicus Value: 71.58

ISSN (e)-2347-176x ISSN (p) 2455-0450

crossref DOI:_https://dx.doi.org/10.18535/jmscr/v6i4.49

Journal Of Medical Science And Clinical Research

\title{
Ovarian Neoplasms-Evaluation by Magnetic Resonance Imaging (MRI)
}

\author{
Authors \\ Dr Debashis Deoghuria, MBBS, MD ${ }^{1}$, Dr Sweta Singh, MBBS ${ }^{2}$ \\ ${ }^{1}$ Associate Professor, Department of Radiodiagnosis, Bankura Sammilani Medical College and Hospital \\ ${ }^{2}$ Post Graduate Trainee, Department of Radiodiagnosis, Bankura Sammilani Medical College and Hospital
}

\section{Abstract}

The present study focuses upon the role of MRI in evaluation of ovarian neoplasm and to compare with clinical, surgical and histopathological data.

\section{Objective}

To evaluate the accuracy of MRI in diagnosis and characterization of ovarian neoplasm into benign and malignant, primarily evaluated by ultrasonography (USG).

\section{Materials and Methods}

The present study was conducted in the Department of Radio diagnosis, Bankura Sammilani Medical College, Bankura in a time span of 1 year from March 2017 to March 2018.A total of 53 patients with lesions of ovarian origin were taken for the study, prior evaluated by ultrasound (HD7 Philips). These patients were referred to us from Department of Gynecology and Obstetrics, Department of General Medicine and Department of General Surgery. All patients in our study underwent pelvic MRI imaging on a 1.5 Tesla scanner (GE). Scanning was performed after a fasting period of 4-6 hours, in supine position with a surface coil placed on the torso covering the entire imaging area.T1,T2,T2 fat saturation, Diffusion restriction (DWI), ADC mapping and POST CONTRAST (Gadolinium dimeglumine was used) images were taken in axial, coronal and sagittal planes. Post processing was done by inbuilt processor.

Descriptive statistical analysis has been carried out in the present study. Significance is assessed at $5 \%$ level of significance. Chi square tesr/Fisher Exact test has been used to find the significance of association of MRI with Histopathological diagnosis/ follow up/ other tests.

The statistical software namely SPSS15.0,STATA 8.0,MedCalc 9.0.1 and Systat 11.0 were used for the analysis of the data and Microsoft word and Excel have been used to generate graphs, tables etc

\section{Results and Observations}

A total of 53 patients with lesions of the ovarian origin (benign, borderline, and malignant) were taken for the purpose of study. This includes 3 patients of PCOD. 
1. Chart showing age distribution of patients in the study.

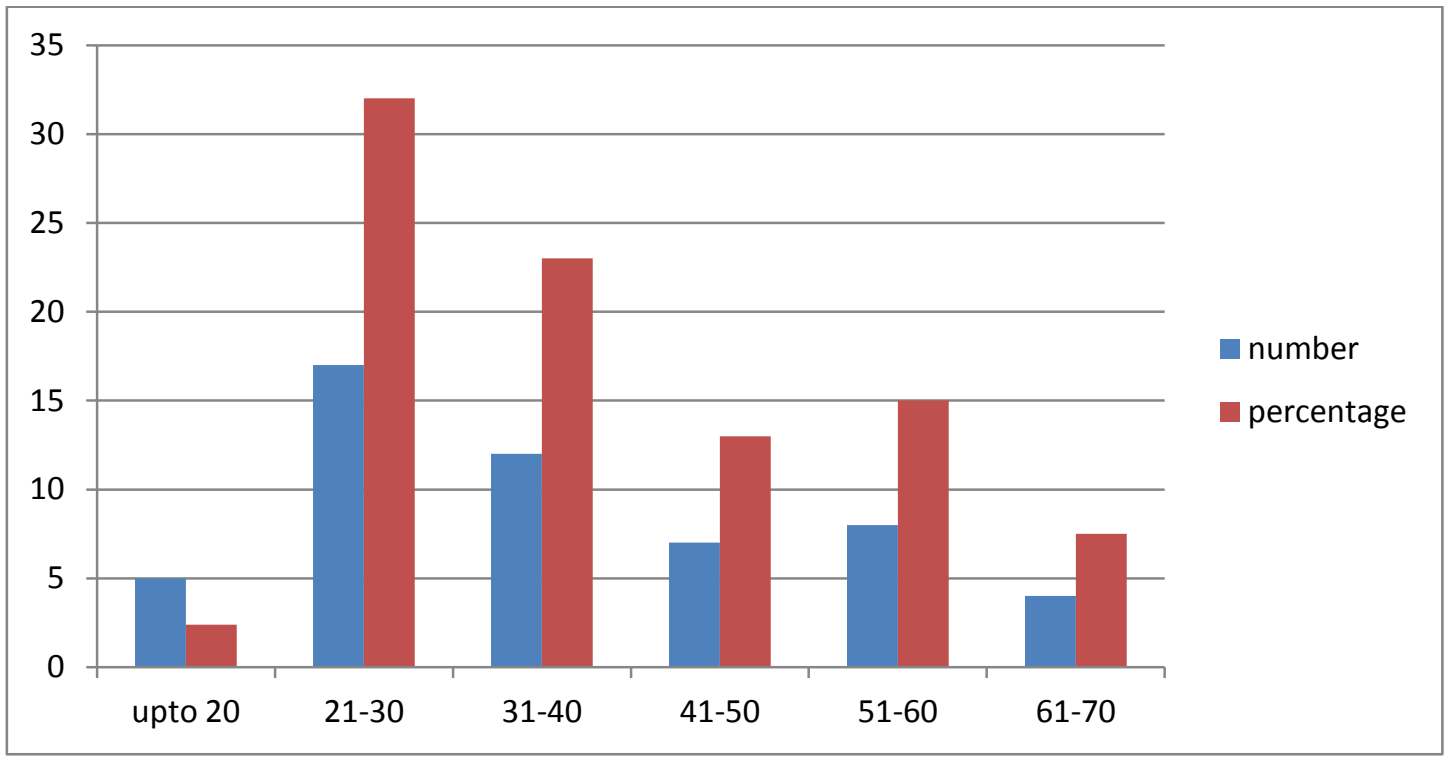

2. Chart showing presenting complaints of patients with benign ovarian pathology

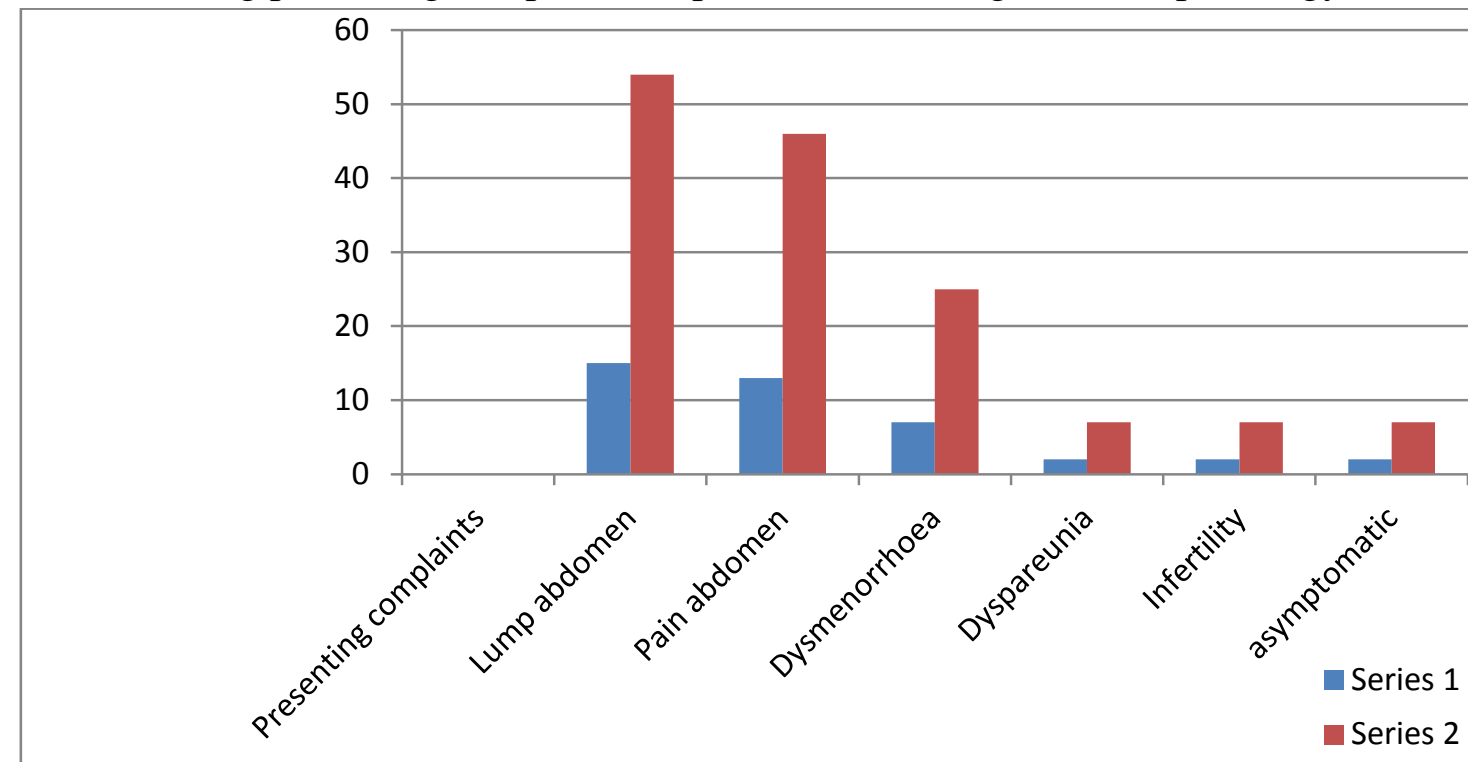

3. Chart showing presenting complaints of patients with malignant ovarian pathology

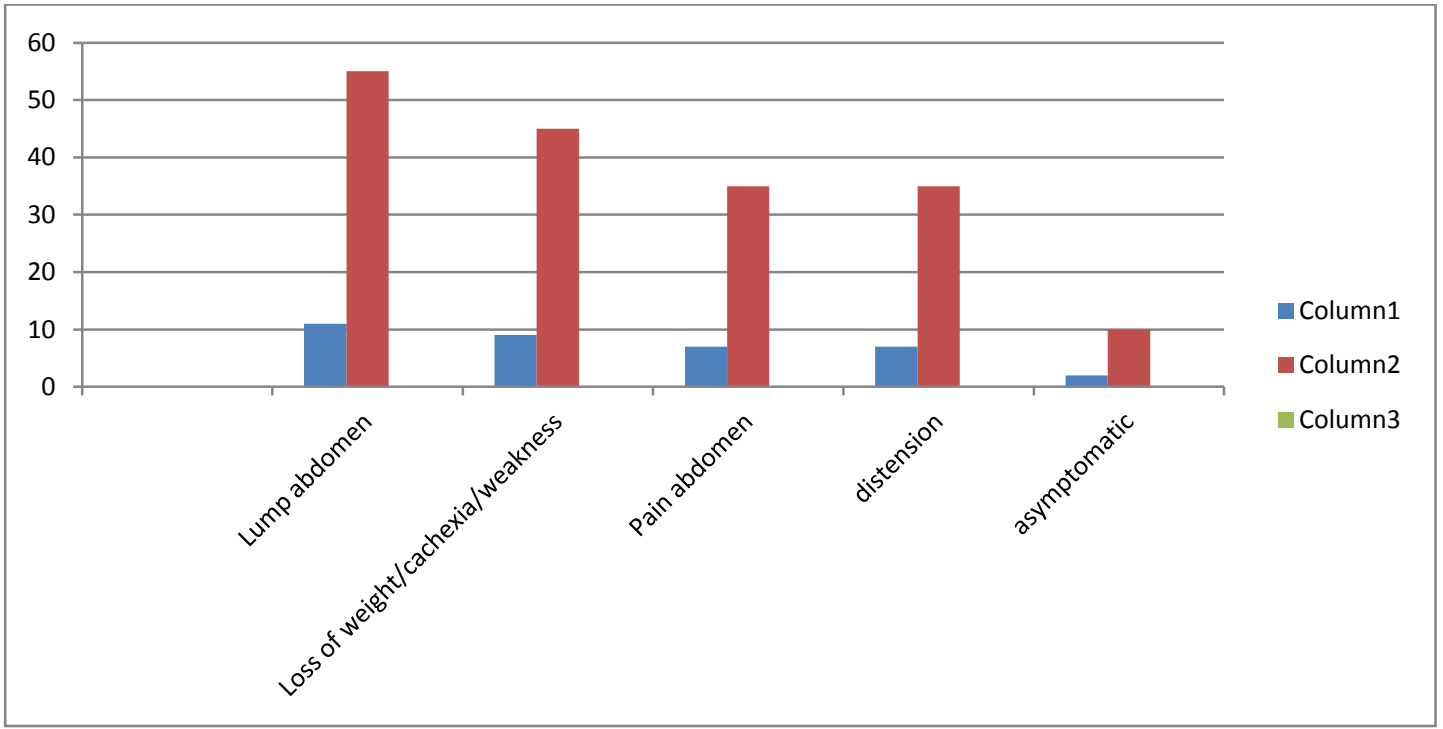


4. Chart showing relationship of malignancy with menstrual status of the patient

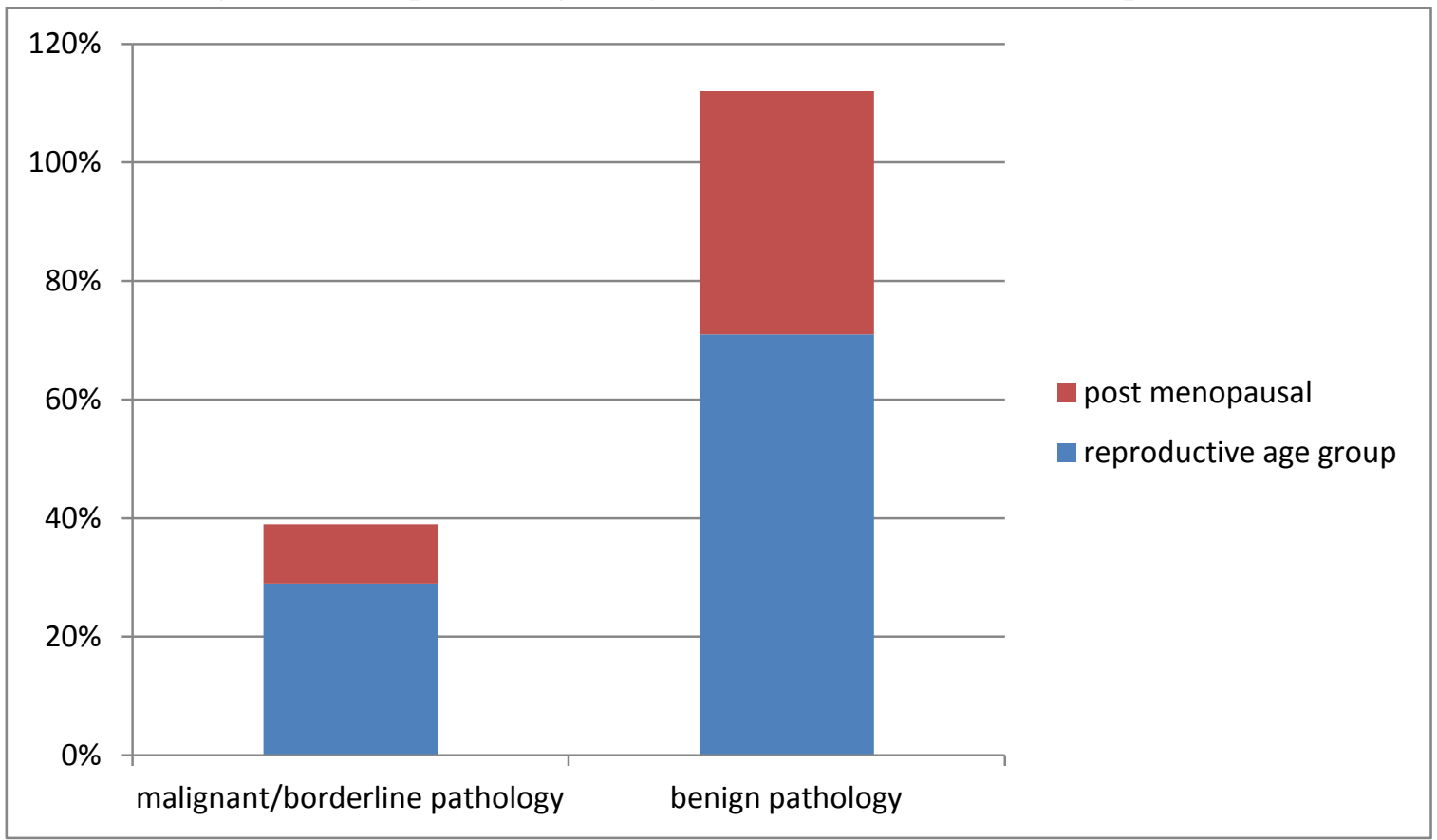

5. Sensitivity, Specificity and accuracy of MRI in differentiating benign from borderline and malignant lesions

There were 72 lesions in 50 patients. MRI diagnosed 50 benign lesions, 3 borderline and 19 malignant lesions. Final diagnosis was established by pathological analysis of all the lesions those were operated. Small simple, haemorrhagic and endometriotic cysts were diagnosed with pathological analysis, follow up imaging or comparison with prior USG. the cases in which the histopathological diagnosis revealed parovarian cystadenoma was omitted from these calculations. Distribution of lesions-

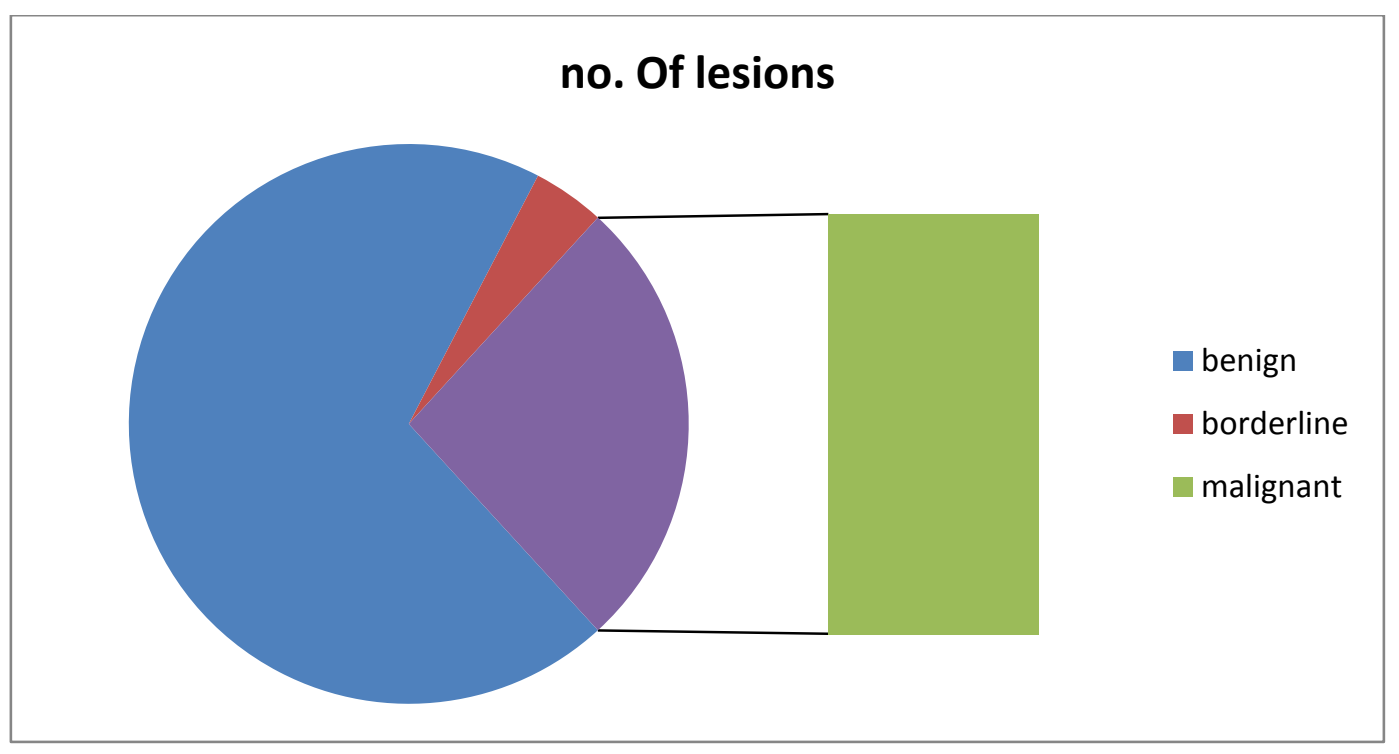

Table showing distribution of lesions according to benign, borderline, and malignant (Histopathological diagnosis)

\begin{tabular}{|l|c|c|c|c|}
\hline type & benign & borderline & malignant & Total \\
\hline No. Of lesions & 46 & 6 & 20 & 72 \\
\hline percentage & $64 \%$ & $8.3 \%$ & $27 \%$ & $100 \%$ \\
\hline
\end{tabular}




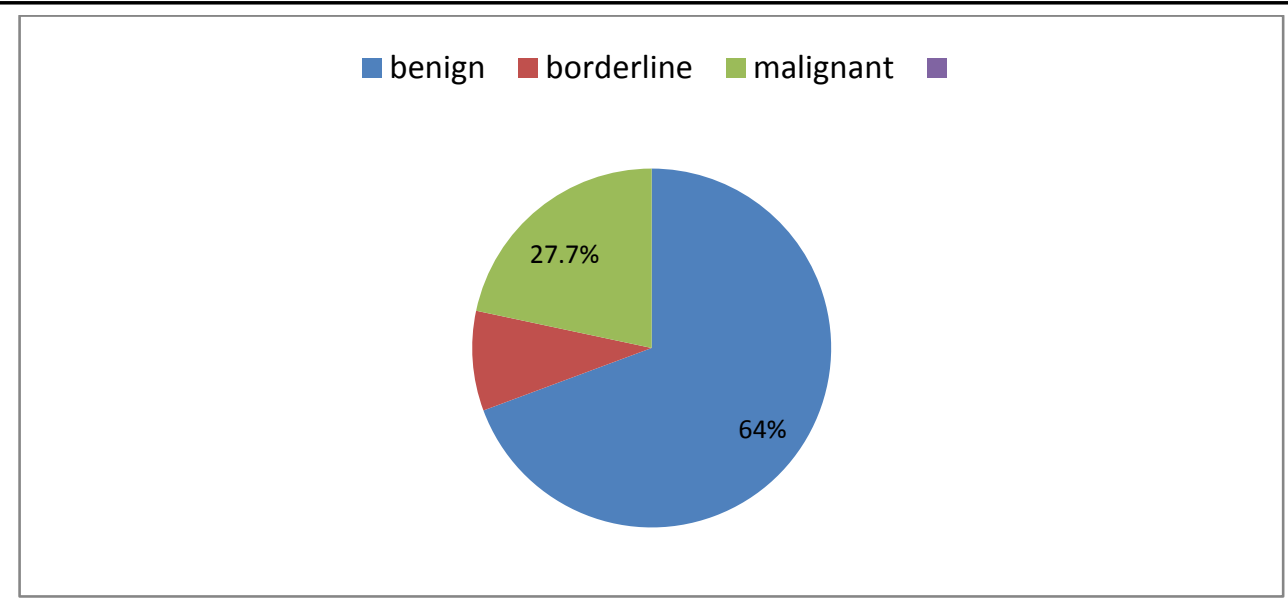

\begin{tabular}{|l|c|c|c|}
\hline DATA ANALYSED & Hp benign & Hp malignant & Total \\
\hline MRI benign & $45(63 \%)$ & $9(13 \%)$ & $54(75 \%)$ \\
\hline MRI borderline/malignant & $1(1 \%)$ & $17(24 \%)$ & $18(25 \%)$ \\
\hline & $46(64 \%)$ & $26(36 \%)$ & $72(100 \%)$ \\
\hline
\end{tabular}

\begin{tabular}{|l|c|c|}
\hline & value & $95 \%$ confidence interval \\
\hline Sensitivity & 97.8 & $88.4-99.9$ \\
\hline Specificity & 65.3 & $44.3-82.7$ \\
\hline Positive predictive value & 83.3 & $70.7-92.0$ \\
\hline Negative predictive value & 94.4 & $72.7-99.8$ \\
\hline P value & $<0.0001$ & \\
\hline Likelihood ratio & 2.82 & \\
\hline $\begin{array}{l}\text { Balanced accuracy of MRI in differentiating } \\
\text { benign/borderline/malignant }\end{array}$ & $81.6 \%$ & \\
\hline
\end{tabular}

Specific imaging features of benign and malignant masses on MRI

\begin{tabular}{|l|c|c|c|c|}
\hline Imaging features & $\begin{array}{c}\text { Malignant/borderline } \\
\text { (total-26) }\end{array}$ & $\begin{array}{c}\text { Percentage } \\
(\%)\end{array}$ & $\begin{array}{c}\text { Benign } \\
\text { (total-32) }\end{array}$ & $\begin{array}{c}\text { Percentage } \\
(\%)\end{array}$ \\
\hline Size $>4 \mathrm{~cm}$ & 26 & 100 & 31 & $97 \%^{1 \mathrm{i}}$ \\
\hline Solid component & 17 & $65 \%$ & 1 & $3 \%$ \\
\hline Solid component with necrosis & 13 & $50 \%$ & 0 & $0 \%$ \\
\hline Papillary projections & 11 & $42 \%$ & 0 & $0 \%$ \\
\hline Thick wall/septa( $>3 \mathrm{~mm})$ & 11 & $42 \%$ & 7 & $22 \%$ \\
\hline
\end{tabular}

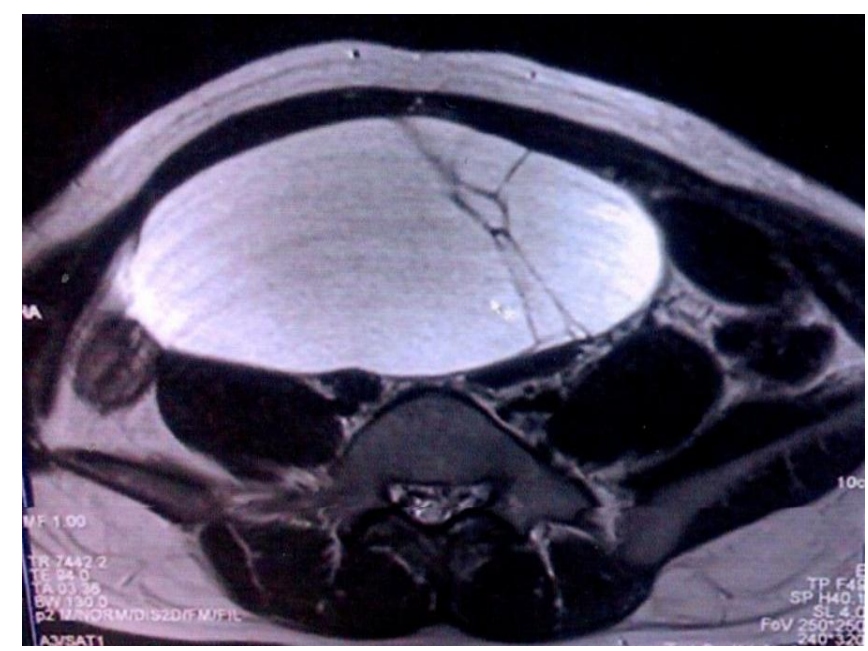

T2 weighted axial image showing multiloculated thin walled cystic lesion with thin septae. Features of benign ovarian neoplasm. 

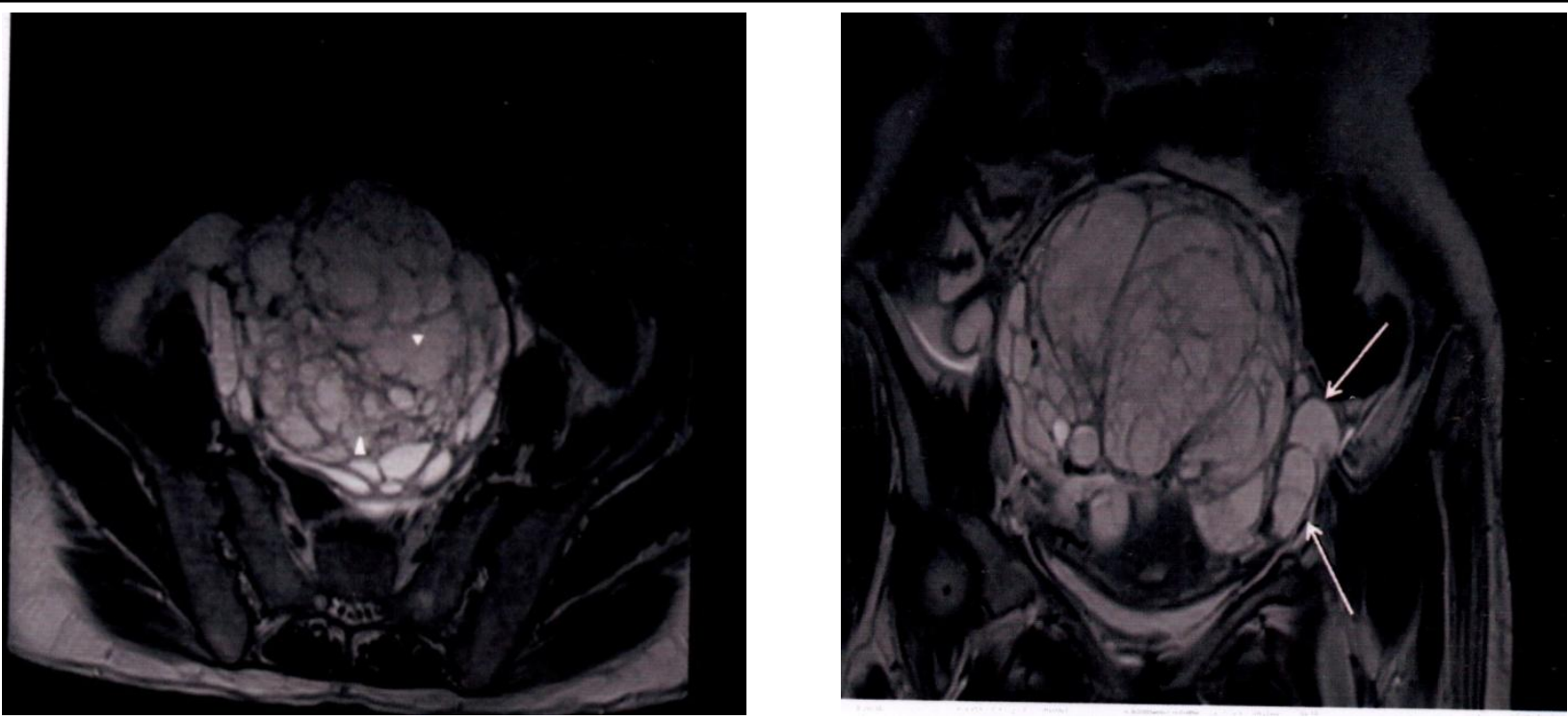

T2 weighted axial and coronal images showing multiloculaed biadnexal cystic lesions, with honeycomb loculi, thin walls, and septa along with multiple papillary projections. Ascites is present. Features of borderline/ malignant ovarian neoplasm.

Bar diagram showing relation of specific imaging features of benign and malignant nature of masses

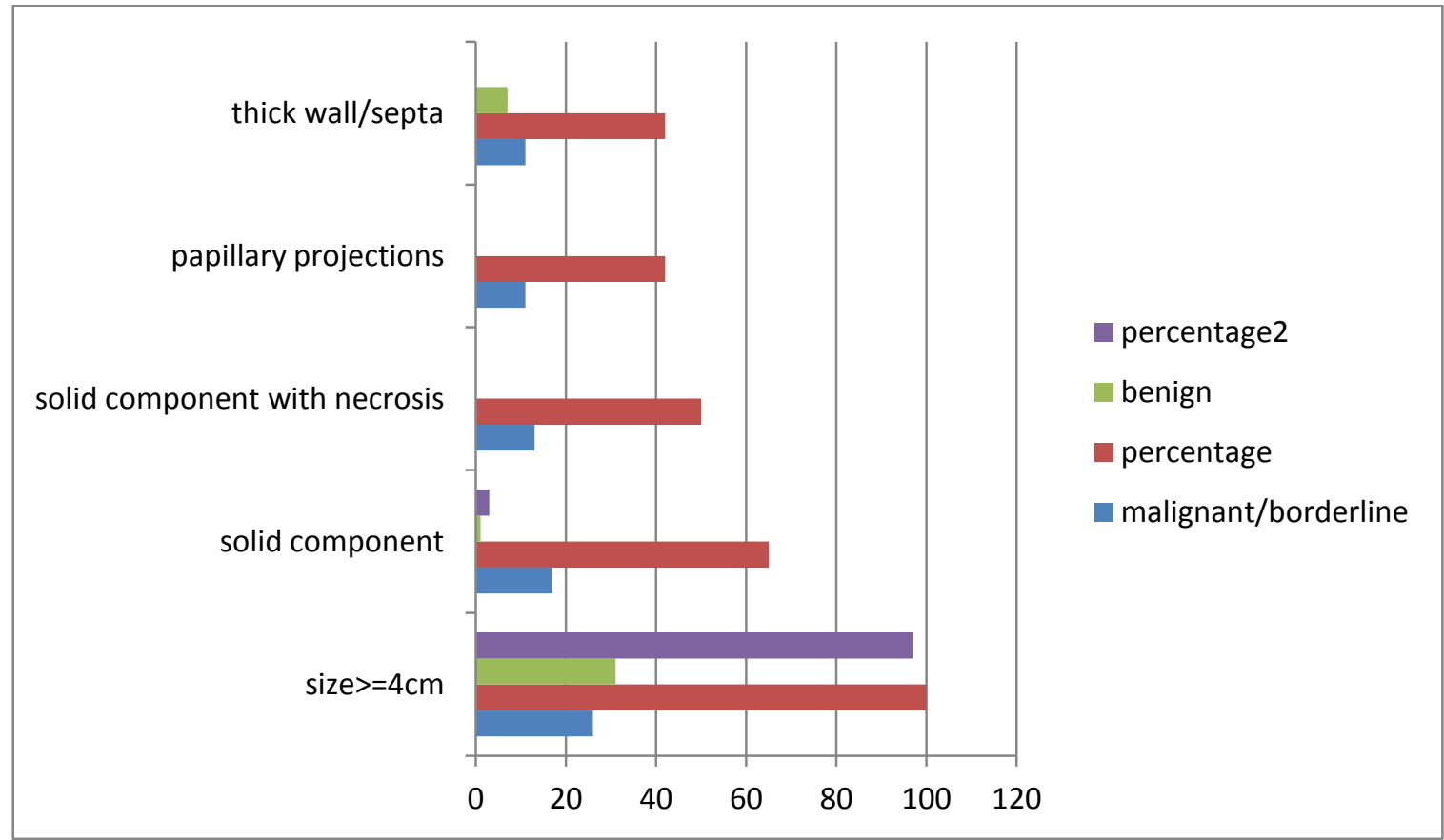

Table showing the distribution of dissemination of the malignant neoplastic lesions in the study

\begin{tabular}{|l|c|c|}
\hline Ascites & 15 & $100 \%$ \\
\hline Pleural effusion & 3 & $20 \%$ \\
\hline Peritoneal dissemination & 6 & $40 \%$ \\
\hline Lymph nodes & 4 & $27 \%$ \\
\hline Invasion & 3 & $20 \%$ \\
\hline Distant metastasis & 2 & $13 \%$ \\
\hline Total number of cases & 15 & \\
\hline
\end{tabular}




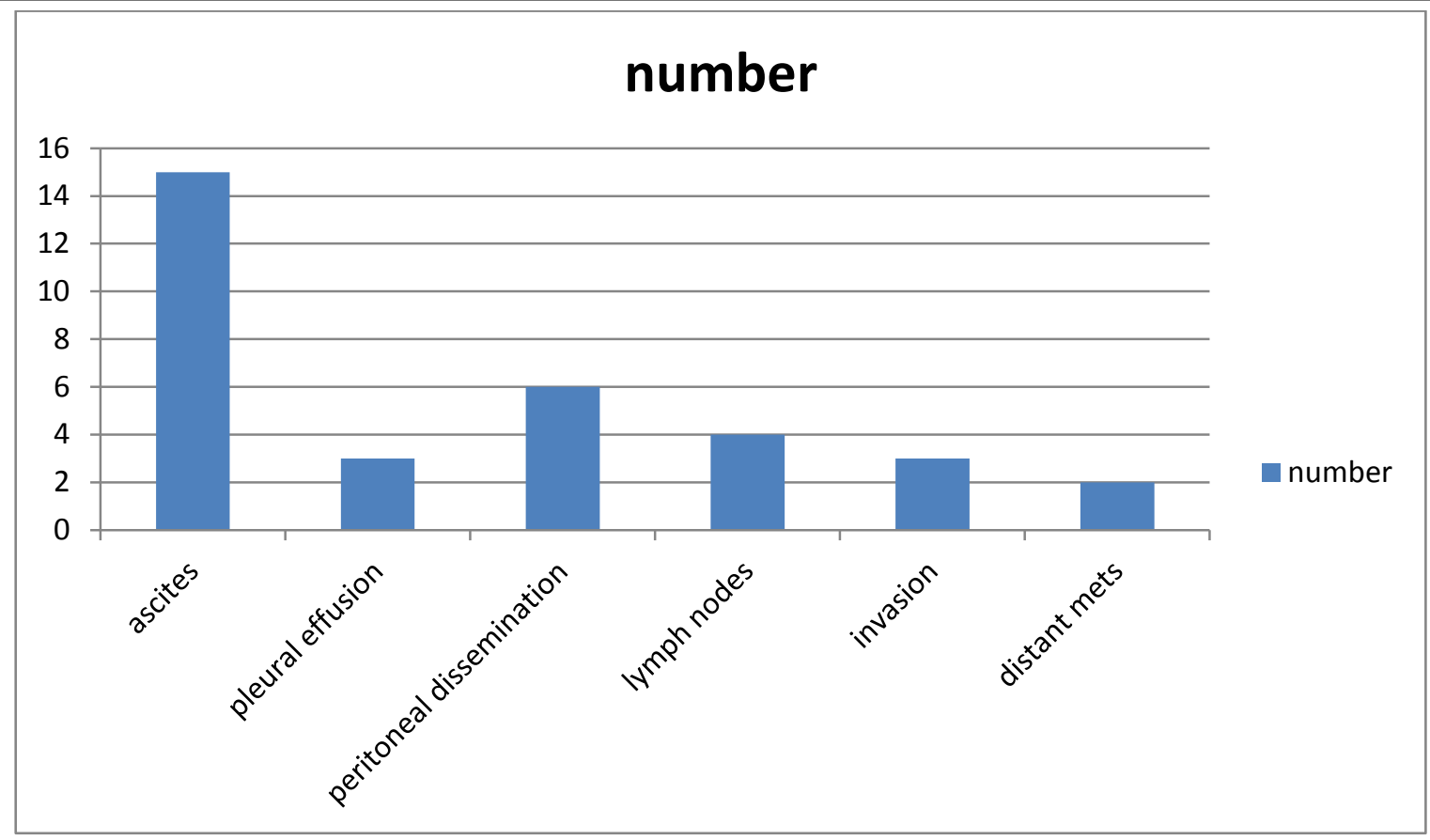

\section{Discussion}

The present series of study consisted of 53 patients who presented with various gynaecological complaints for ultrasound to the Department of Radiodiagnosis, Bankura Sammilani Medical College and Hospital.

The most common age group in which we found ovarian masses was 21-30 years (32\%), followed by $31-40$ years. The commonest presenting complaint in both benign and malignant ovarian masses was feeling of lump in the abdomen, followed by pain abdomen in benign cases and systemic symptoms of weight loss, generalised weakness and cachexia in malignant cases. Malignant cases were predominantly seen in older age group (61-70 years).

Post processing, we found $81.6 \%$ accuracy, $97.8 \%$ sensitivity, $65.3 \%$ specificity of MRI in differentiating benign from malignant lesions. The larger confidence interval in specificity, however, indicates less precise estimate due to small sample size.

\section{Summary and Conclusion}

The study was a prospective observational study conducted in Department of Radio diagnosis, Bankura Medical College and Hospital, Bankura, during a period of 1 year.
The following conclusions were drawn-

MRI is sensitive and accurate in distinguishing between benign, borderline and malignant lesions. Features indicative of malignancy include presence of both solid and cystic areas within a lesion, necrotic component, thick wall, thick septae, papillary projections, ascites, implants (peritoneal, mental and/or mesenteric) or lymphadenopathy.

In conclusion, it can be said that due to excellent depiction of pelvic anatomy and absence of ionising radiations, MRI is an excellent tool for the assessment of disorders of the ovary in women of child bearing age and post menopausal status

\section{References}

1. Ghossain MA, Buy JN, Ligneres C, et al. Epithelial tumors of the ovary: comparison of MR and CT findings. Radiology. 1991; 181:863-70. [PubMed]

2. Sohaib SA, Mills TD, Sahdev A, et al. The role of magnetic resonance imaging and ultrasound in patients with adnexal masses. Clin Radiol. 2005; 60:340-8. [PubMed]

3. Yamashita Y, Torashima M, Hatanaka Y, et al. Adnexal masses: accuracy of characterization with transvaginal US and 
precontrast and postcontrast MR imaging. Radiology. 1995; 194:557-65. [PubMed]

4. Komatsu T, Konishi I, Mandai M, et al. Adnexal masses: transvaginal US and gadolinium-enhanced MR imaging assessment of intratumoral structure. Radiology. 1996; 198:109-15. [PubMed]

5. Rieber A, Nussle K, Stohr I, et al. Preoperative diagnosis of ovarian tumors with MR imaging: comparison with transvaginal sonography, positron emission tomography, and histologic findings. AJR Am J Roentgenol. 2001; 177:123-9. [PubMed]

6. Kinkel K, Lu Y, Mehdizade A, Pelte MF, Hricak $H$. Indeterminate ovarian mass at US: incremental value of second imaging test for characterization-meta-analysis and Bayesian analysis. Radiology.2005;236:85-94. [PubMed]

7. Sohaib SA, Sahdev A, Van Trappen PO, Jacobs IJ, Reznek RH. Characterization of adnexal mass lesions on MR imaging. AJR Am J Roentgenol. 2003;180:1297-304. [PubMed]

8. Hricak H, Chen M, Coakley FV, et al. Complex adnexal masses: detection and characterization with MR imagingmultivariate analysis. Radiology. 2000;214:39-46. [PubMed]

9. Forstner R, Hricak H, White S. CT and MRI of ovarian cancer (Review) Abdom Imaging. 1995;20:2-8.[PubMed]

10. Buy JN, Ghossain MA, Sciot C, et al. Epithelial tumors of the ovary: CT findings and correlation with US. Radiology. 1991;178:811-18. [PubMed]

11. Troiano RN, Lazzarini KM, Scoutt LM, Lange RC, Flynn SD, McCarthy S. Fibroma and fibrothecoma of the ovary: MR imaging findings. Radiology. 1997;204:795-8. [PubMed]
12. Semelka RC, Lawrence PH, Shoenut JP, et al. Primary ovarian cancer: prospective comparison of contrast-enhanced CT and pre-and postcontrast, fat-suppressed MR imaging, with histologic correlation. J Magn Reson Imaging. 1993;3:99-106. [PubMed]

13. Prayer L, Kainz C, Kramer J, et al. CT and MR accuracy in the detection of tumor recurrence in patients treated for ovarian cancer. J Comput Assist Tomogr. 1993;17:626-32. [PubMed]

14. 14.. Goldhirsch A, Triller JK, Greiner R, Dreher E, Davis BW. Computed tomography prior to second-look operation in advanced ovarian cancer. Obstet Gynecol. 1983;62:630-4. [PubMed]

15. Moskovic E, Fernando I, Blake P, Parsons C. Lymphography - current role in oncology. $\mathrm{Br}$ J Radiol.1991;64:422-7. [PubMed]

16. Silverman PM, Osborne M, Dunnick NR, Bandy LC. CT prior to second-look operation in ovarian cancer. AJR Am J Roentgenol. 1988;150:829-32. [PubMed]

17. Forstner R, Hricak H, Powell CB, Azizi L, Frankel SB, Stern JL. Ovarian cancer recurrence: value of MR imaging. Radiology. 1995;196:715-20. 